\title{
Preparation of a polyclonal antibody against hypericin synthase and localization of the enzyme in red-pigmented Hypericum perforatum $L$. plantlets
}

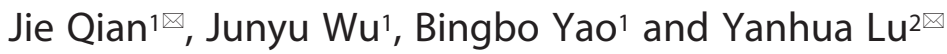 \\ 1School of Life Science and Technology, Tongji University, Shanghai, China; 2 State Key Laboratory of Bioreactor Engineering, East China Univer- \\ sity of Science and Technology, Shanghai, China
}

\begin{abstract}
Hypericum perforatum is well known for its antidepressant and anti-inflammatory activities, for which hypericin and its derivatives are indicated to be the most active compounds. Hypericin synthase (Hyp-1) is the only protein proven to catalyze the synthesis of hypericin. In this study, the full-length cDNA of Hyp- 1 was chemically synthesized according to the Hyp-1 sequence in GenBank (accession no. AY148090) and then cloned into the plasmid pET22b. Hyp-1 was expressed in Escherichia coli BL21 (DE3) and purified with a Ni-NTA column. The purified protein was used to immunize New Zealand white rabbits, from which an antiserum was purified by protein $\mathrm{G}$ affinity chromatography. The polyclonal antibody against Hyp-1 provides a valuable tool for the study of hypericin biosynthesis in $H$. perforatum. Expression of Hyp-1 and the cellular distribution of hypericin were analyzed in different organs of red-pigmented $H$. perforatum plantlets. The black glands were not the only site of hypericin accumulation and the results indicated that hypericin might be synthesized in mesophyll cells or in tissues of the root and/or stem and then transported to the glands. This work provides a foundation for further investigation of the regulatory mechanism of hypericin synthesis during the development of $H$. perforatum.
\end{abstract}

Key words: hypericin synthase, hypericin, Hypericum perforatum, polyclonal antibody, tissue localization

Received: 04 June, 2012; revised: 16 October, 2012; accepted: 07 November, 2012; available on-line: 16 November, 2012

\section{INTRODUCTION}

Hypericum perforatum L. (St John's wort) is a herbaceous perennial species widely distributed in the northern temperate zone. It is used for the treatment of depression (Stevinson \& Ernst, 1999; Maidment, 2000). Hypericin and its derivatives are indicated to be the major bioactive compounds of $H$. perforatum. A large number of experiments have proven that the hypericin group is effective against depression, cancer and several viruses, including human immunodeficiency virus (HIV), cytomegalovirus, human papillomavirus (HPV), and herpes (Stevinson \& Ernst, 1999; Liu et al., 2000; Agostinis et al., 2002; Taher et al., 2002; Miskovsky, 2002). It is hoped that hypericins will provide potential leads for new therapeutics (Karioti \& Bilia, 2010).

In 2003, Bais et al. (2003) cloned and characterized a gene, termed hypericin synthase $\left(H_{y p}-1\right)$, involved in hypericin biosynthesis from $H$. perforatum cell cultures and demonstrated that the encoded protein was responsible for hypericin biosynthesis after the administration of emodin, a precursor of hypericin, under in vitro conditions. Hyp-1 is a monomeric protein composed of 159 residues with $17.8 \mathrm{kDa}$ mass, and shows about 50\% amino-acid sequence similarity to plant pathogenesis-related class 10 (PR-10) proteins. Crystal structure analysis confirmed that it was indeed a member of the class of plant PR-10 proteins (Fernandes et al., 2008; Michalska et al., 2010). Kosuth et al. (2007) studied the Hyp-1 mRNA expression level in different organs of $H$. perforatum seedlings at early stages of development. The highest level of expression was found in roots. In contrast, anatomical and histological studies showed that hypericin was accumulated in the so-called dark glands or black nodules, which are distributed on leaf margins and flower petals of H. perforatum (Curtis \& Lersten, 1990; Fornasiero et al., 1998), and a positive correlation between the size and number of dark glands and the overall content of hypericin in the plant organ was demonstrated (Zobayed et al., 2006).

As mRNA levels may not necessarily correlate with the protein level (Gygi et al., 1999; Futcher et al., 1999), it is difficult to distinguish whether the mRNA level corresponds with the protein content or hypericin is synthesized elsewhere in the plant and then transported to the glands. Thus it is preferable to explore expression of Hyp-1 directly at the protein level. In this study, we report the cloning and expression of $\mathrm{Hyp}^{-1}$ in E. coli, purification of recombinant protein, and generation of a polyclonal antibody against the Hyp-1 protein. Additionally, we studied expression of the Hyp- 1 protein by immunofluorescence and explored the distribution of hypericins according to their physical and chemical properties in different organs of red-pigmented $H$. perforatum plantlets.

\section{MATERIALS AND METHODS}

Strains and Reagents. Restriction enzymes and T4 DNA ligase were purchased from Takara (Dalian, China). Taq Plus I DNA polymerase, dNTPs and primers were from Sangon Biotechnology Corp. (Shanghai, China). IPTG, Freund's complete adjuvant and Freund's incomplete adjuvant were obtained from Sigma. Horserad-

e-mail: Jie Qian: qianjie116@tongji.edu.cn; Yanhua Lu: luyanhua@ ecust.edu.cn

Abbreviations: $B S A$, bovine serum albumin; $E C L$, enhanced chemiluminescence; ELISA, enzyme-linked immunosorbent assay; Hyp-1, hypericin synthase; IPTG, isopropyl- $\beta$-D-thiogalactopyranoside; LB, Luria-Bertani; PBS, phosphate buffered saline; PCR, polymerase chain reaction; PVDF, polyvinylidene difluoride; TMB, 3,3',5,5'-tetramethylbenzidine. 
ish peroxidase (HRP)-labeled goat anti-rabbit IgG, the Plasmid Extraction Kit and MinElute Gel Extraction Kit were purchased from Beyotime Institute of Biotechnology (Shanghai, China). Ni-NTA columns were purchased from York Biotechnology Corp. (Shanghai, China) and HiTrap Protein G columns were purchased from GE Healthcare. Escherichia coli BL21 (DE3), DH5 $\alpha$ and the expression vector pET22b were kindly donated by the Model Organisms Laboratory, Tongji University, Shanghai, China. Other conventional chemical reagents were all domestic AR grade.

Plasmid construction and transformation. The full-length cDNA of $H y p-1$ was chemically synthesized by Sangon Biotechnology Corp. (Shanghai, China), according to the Hyp-1 sequence in GenBank (accession no. AY148090). The cDNA was inserted into the cloning vector pUC57 to yield pUC57-Hyp-1. PCR amplification of the full-length cDNA of $H_{y p-1}$ was performed using the forward and reverse primers 5'- GGGGA TCC GAT GGC GGC GTA CAC TAT TGT-3' (underlined nucleotides indicate the Bam $\mathrm{HI}$ restriction site) and 5'-CCCCTC GAG AGC GAA AAC TTC AGG ATT AG-3'(underlined nucleotides indicate the XhoI restriction site), respectively. After double digestion with $X h o \mathrm{I}$ and BamHI, the PCR products and the empty vector $\mathrm{pET} 22 \mathrm{~b}$ were ligated overnight at room temperature. The ligation product, pET22b-Hyp-1, was transformed into competent E. coli $\mathrm{DH} 5 \alpha$ and recombinant colonies were selected for ampicillin $(100 \mu \mathrm{g} / \mathrm{ml})$ resistance. Single colonies were selected and the isolated plasmid was sequenced to verify the presence of the correct insert by Sangon Biotechnology Corp. (Shanghai, China). All DNA manipulations were performed as described by Sambrook \& Russell (2001).

Expression of the Hyp-1 protein. E. coli BL21 (DE3) cells were transformed with pET22b-Hyp-1. A single transformed colony was inoculated into LB medium supplemented with ampicillin $(100 \mu \mathrm{g} / \mathrm{ml})$ and grown at $37^{\circ} \mathrm{C}$ while shaken at $260 \mathrm{rpm}$ overnight. The next day, the bacteria culture was diluted up to 100 times with fresh TB medium $(1.2 \%$ (w/v) tryptone, $2.4 \%(\mathrm{w} / \mathrm{v})$ yeast extract, $0.4 \%(\mathrm{v} / \mathrm{v})$ glycerol, 17 $\left.\mathrm{mM} \mathrm{KH}_{2} \mathrm{PO}_{4}, 72 \mathrm{mM} \mathrm{K} \mathrm{HPO}_{4}\right)$ in a $500 \mathrm{ml}$ shake flask. The culture was grown at $37^{\circ} \mathrm{C}$ until the $\mathrm{OD}_{600}$ reached 0.7. IPTG (final concentration $100 \mu \mathrm{M}$ ) was added to induce expression of the recombinant Hyp-1 protein and the culture was agitated overnight (for about $12 \mathrm{~h}$ ) at $26^{\circ} \mathrm{C}$. Cells were harvested by centrifugation at 5,000 rpm for $10 \mathrm{~min}$ at $4^{\circ} \mathrm{C}$ and the pellet was resuspended in $20 \mathrm{ml}$ cold STE buffer $(50 \mathrm{mM}$ Tris/HCl, $1 \mathrm{mM}$ EDTA, $0.4 \mathrm{M} \mathrm{NaCl}, \mathrm{pH}$ 8.0). The cells were lysed by sonication $(200 \mathrm{~W}, 25$ cycles of a 2 -s pulse separated by a 3-s break) in an ice-water bath. The soluble and insoluble cell fractions were separated by centrifugation of the cell lysate at $15000 \mathrm{rpm}$ for $20 \mathrm{~min}$ at $4^{\circ} \mathrm{C}$. The protein patterns of the cell lysate fractions were analyzed by SDS/PAGE using a 15\% gel according to the method of Laemmli (1970). The expression and solubility of the recombinant protein was identified by staining the gel with Coomassie Blue R-250 and visualization of an extra protein band of the predicted size.

Solubilization and purification of recombinant protein. Proteins expressed in insoluble particles were solubilized with $2 \mathrm{M}$ urea. For that, the sediment after sonication was washed with $15 \mathrm{ml}$ buffer A $(50 \mathrm{mM}$ Tris/ $\mathrm{HCl}, 0.4 \mathrm{M} \mathrm{NaCl}, \mathrm{pH} 8.0$ ) at room temperature and centrifuged twice at $10,000 \mathrm{rpm}$ for $10 \mathrm{~min}$ at $4^{\circ} \mathrm{C}$. The final pellets comprising the inclusion bodies were solubilized by homogenization in $15 \mathrm{ml}$ of buffer A containing
$2 \mathrm{M}$ urea at room temperature for $30 \mathrm{~min}$. The solution was centrifuged at $18000 \mathrm{rpm}$ for $15 \mathrm{~min}$ at $4^{\circ} \mathrm{C}$. The recombinant protein was purified from the supernatant by affinity chromatography using Ni-NTA columns (York Biotechnology Corp., Shanghai, China) pre-equilibrated with buffer A. Non-binding proteins were washed from the column using 15 column volumes of buffer $\mathrm{A}$ with $30 \mathrm{mM}$ imidazole, before eluting specifically bound protein using eight column volumes of buffer A with $200 \mathrm{mM}$ imidazole. Fractions of $1 \mathrm{ml}$ were eluted and analyzed by $15 \%$ SDS/PAGE. Fractions containing the recombinant protein were pooled and dialysed against 50 volumes of buffer $(50 \mathrm{mM}$ Tris $/ \mathrm{HCl}, 50 \mathrm{mM} \mathrm{NaCl}$, $5 \%(\mathrm{v} / \mathrm{v})$ glycerol, $\mathrm{pH} 8.0)$ at $4^{\circ} \mathrm{C}$ to remove the imidazole and urea, and to promote protein refolding. The buffer was changed four times every $12 \mathrm{~h}$. The protein concentration was determined by the Bradford method using BSA as a standard (Bradford, 1976). The final recombinant protein was stored at $-20^{\circ} \mathrm{C}$.

Polyclonal antibody preparation and purification. Two New Zealand white rabbits were simultaneously immunized with the recombinant protein according to the following procedure. Before immunization, the rabbits were bled from the ear vein and the preimmune serum was collected by centrifugation of the blood samples. The rabbits were immunized intracutaneously with 500 $\mu \mathrm{g}$ of fusion protein emulsified with an equal volume of Freund's complete adjuvant. Two days later, the rabbits were immunized with the same mixture. Three weeks later, a mixture of $500 \mu \mathrm{g}$ fusion protein and the same volume of incomplete Freund's adjuvant were injected into the rabbits. Seven days later, the blood serum was harvested from the blood from the rabbits' carotid artery. The polyclonal antibody was purified with a HiTrap Protein $G$ column using the AKTA FPLC system (GE Healthcare) following a standard protocol. The purified antibody was neutralized immediately with $1 \mathrm{M}$ Tris $/ \mathrm{HCl}$ $(\mathrm{pH} 9.0)$ and stored in $0.02 \%$ sodium azide at $-20^{\circ} \mathrm{C}$.

Western blotting. Western blotting was performed to detect the specificity of the polyclonal antibody, using the preimmune serum as a negative control. The purified protein was separated by $15 \%$ SDS/PAGE and electroblotted using Towbin transfer buffer $(25 \mathrm{mM}$ Tris, $192 \mathrm{mM}$ glycine) onto a PVDF membrane (Millipore) with a semidry electroblotting apparatus (Bio-Rad) at $100 \mathrm{~mA}$ for $35 \mathrm{~min}$. The membrane was blocked with TBST (50 mM Tris/ $\mathrm{HCl}, 150 \mathrm{mM} \mathrm{NaCl}$, and $0.1 \%$ Tween-20, pH 7.4) containing 5\% skimmed milk for 1 $\mathrm{h}$ at room temperature and then incubated with the rabbit anti-Hyp-1 antibody (1:2000 dilution in TBST with $5 \%$ skimmed milk) overnight at $4^{\circ} \mathrm{C}$. After washing three times for $10 \mathrm{~min}$ each with TBST, the membrane was incubated with the goat anti-rabbit $\mathrm{IgG}$ conjugated to HRP, diluted 1:1200 in TBST with 5\% skimmed milk, for $1 \mathrm{~h}$ at room temperature. The membrane was washed three times with TBST and the antibody-antigen complex was visualized with the ECL ${ }^{\mathrm{TM}}$ Western Blotting Detection Kit (Amersham Biosciences).

Antiserum titer determination by ELISA. Indirect ELISA for detection of antibody titers was performed as follows, using the preimmune serum as a negative control. Ninety-six-well immunoplates were coated with $100 \mu \mathrm{l}$ of the recombinant protein sample $(10 \mu \mathrm{g} / \mathrm{ml}$ in $50 \mathrm{mM}$ carbonate buffer, $\mathrm{pH} 9.6)$ overnight at $4^{\circ} \mathrm{C}$. The following day, the plates were washed three times with PBST (PBS with 0.1\% Tween-20 adjusted to $\mathrm{pH} 7.2$ ) and treated with $200 \mu \mathrm{l}$ of blocking buffer (PBS with 5\% skimmed milk) for $1 \mathrm{~h}$ at $37^{\circ} \mathrm{C}$. Following several washes with PBST, $200 \mu$ l of anti-Hyp-1 antibody (1:2000 
dilution in blocking buffer) was added to the first well and serially diluted. After reaction for $1 \mathrm{~h}$ at $37^{\circ} \mathrm{C}$, the plates were washed 10 times with PBST and then incubated with $100 \mu \mathrm{l}$ of HRP-labeled goat anti-rabbit IgG (10000-fold dilution in blocking buffer) for $1 \mathrm{~h}$ at $37^{\circ} \mathrm{C}$. After washing 10 times with PBST, $100 \mu$ l of substrate solution $(75 \mu \mathrm{g} / \mathrm{ml}$ TMB in $24 \mathrm{mM}$ citrate buffer solution, $\mathrm{pH} 5.0$, containing $0.03 \% \mathrm{H}_{2} \mathrm{O}_{2}$ ) was added to each well and incubated for $15 \mathrm{~min}$ at room temperature. To stop the reaction, $50 \mu \mathrm{l}$ of Stop Solution $(2 \mathrm{~mol} / 1$ $\mathrm{H}_{2} \mathrm{SO}_{4}$ ) was used. The absorbance values at $450 \mathrm{~nm}$ were measured with a ELX800 Microplate Reader (BioTek Instruments). The antibody titer is defined as the highest dilution of serum at which the $A_{450}$ ratio $\left(A_{450}\right.$ of postimmunization sera $/ A_{450}$ of preimmunization sera) is greater than 2.1 .

Detection of the endogenous Hyp-1 protein in $\boldsymbol{H}$. perforatum. The polyclonal antibody was used to detect the endogenous Hyp-1 protein in $H$. perforatum by Western blotting. Samples were taken from H. perforatum calli, plantlets cultured in vitro, transplants of $H$. perforatum cultured ex vitro, and whole plants of Arabidopsis thaliana (the latter as a negative control). Total protein from the four samples was prepared as follows. The samples were cut into pieces and ground into a fine powder under liquid nitrogen in a mortar. The powder was transferred to an Eppendorf tube and the tube filled with $500 \mu \mathrm{l}$ of extraction buffer $(50 \mathrm{mM}$ Tris $/ \mathrm{HCl}, 10 \%$ (v/v) glycerol, $5 \% \beta$-mercaptoethanol, $6 \mathrm{M}$ urea, $\mathrm{pH} 8.0$ ) and incubated overnight at $4^{\circ} \mathrm{C}$. After centrifugation at $13000 \mathrm{rpm}$ for $20 \mathrm{~min}$ at $4^{\circ} \mathrm{C}$, the supernatant was transferred to a clean tube and mixed with five volumes of precooled acetone to remove the pigments and precipitate the proteins. The tubes were centrifuged at $13000 \mathrm{rpm}$ at $4^{\circ} \mathrm{C}$ for $10 \mathrm{~min}$ and the pellet was air-dried at $-20^{\circ} \mathrm{C}$ to remove residual acetone. The pellet was then dissolved in $40 \mu \mathrm{l}$ of extraction buffer. Protein samples were separated by $15 \%$ SDS/PAGE and visualized by western blotting following the protocol mentioned above.

Specimen preparation. A red-pigmented $H$. perforatum plantlet was generated in our laboratory (Fig. 1). Red pigmentation in $H$. perforatum was an appealing trait because hypericin is a red-colored anthraquinone derivative. Leaves, stalks and roots of red-pigmented plantlets were collected and fixed overnight at $4^{\circ} \mathrm{C}$ in a fixative composed of $10 \mathrm{mM}$ precooled PBS ( $\mathrm{pH} 7.4$ ) with 4\% paraformaldehyde, exhausting the air until the tissue samples had completely soaked into the fixative. The samples were dehydrated in a graded ethanol series for $1 \mathrm{~h}$ at each dilution. Absolute ethanol was replaced by a xylene series $(33.3,50,66.7$ and $100 \%, \mathrm{v} / \mathrm{v})$, after which the samples were gradually infiltrated with paraffin at $60^{\circ} \mathrm{C}$. The paraffin-embedded samples were sectioned $(8 \mu \mathrm{m}$ thickness) using a Leica RM2016 microtome (Leica, Germany). The sections were placed on glass slides coated with $2 \%(\mathrm{v} / \mathrm{v}) 3$-aminopropyltriethoxysilane (Sigma) in acetone and dried overnight at $38^{\circ} \mathrm{C}$.

Immunofluorescence localization of Hyp-1. Hyp-1 was localized using immunofluorescence analysis. Dried sections were deparaffinized with xylene and rehydrated in an ethanol-water series. After immersion in $10 \mathrm{mM}$ PBS ( $\mathrm{pH} \mathrm{7.4)}$ for $6 \mathrm{~min}$, the slides were blocked with $10 \%$ normal goat serum in $10 \mathrm{mM}$ PBS for $20 \mathrm{~min}$ at room temperature, and then incubated with the rabbit anti-Hyp-1 polyclonal antibody (1:1000 dilution) overnight in a humidity chamber at $4^{\circ} \mathrm{C}$. The slides were washed vigorously three times with PBS. Next, $200 \mu \mathrm{l}$ of secondary antibody (1:200 dilution of the goat anti-rabbit IgG-FITC-conjugate, Santa Cruz) was added to the

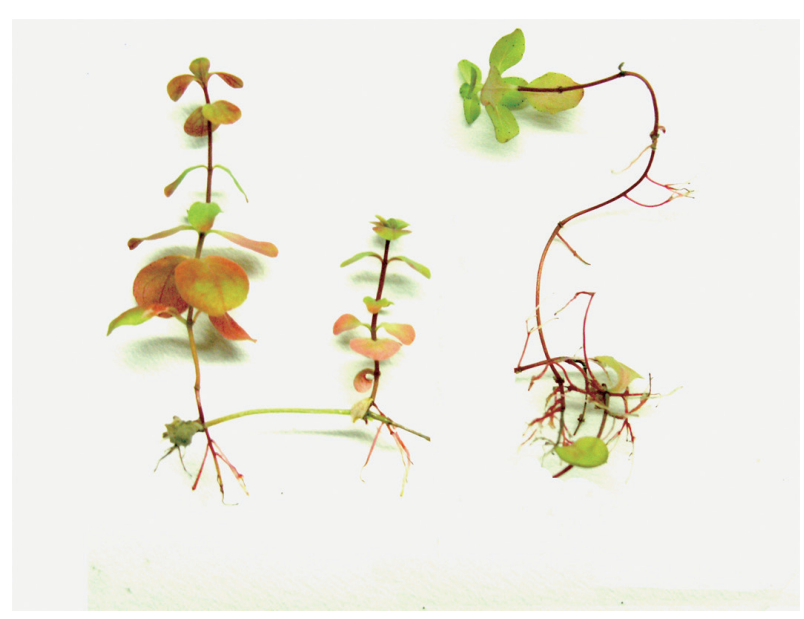

Figure 1. Study material: red-pigmented Hypericum perforatum plantlet

slides and incubated for $1 \mathrm{~h}$ at room temperature. After washing vigorously three times with PBS, the slides were mounted with antifade mounting medium (Beyotime) and viewed with a fluorescence microscope (Olympus BX41, Olympus, Japan).

Histochemical analysis of hypericins. Histochemical analyses were undertaken to detect the presence of hypericin and its derivatives in different parts of the plant. After deparaffinization and rehydration as described previously, some of the sections were observed under blue light without staining with a fluorescence microscope (Maggi et al., 2004). Other sections were incubated with $5 \% \mathrm{NaOH}$ for $10 \mathrm{~s}$ at room temperature and observed under white light (Liang, 1988; Liu \& Hu, 1999).

\section{RESULTS}

\section{Constructing the prokaryotic expression vector}

The full-length cDNA of $H_{y p-1}$ was amplified by PCR with Taq Plus I DNA polymerase using the plasmid pUC57-Hyp-1 as a template. A 0.6-kb DNA fragment

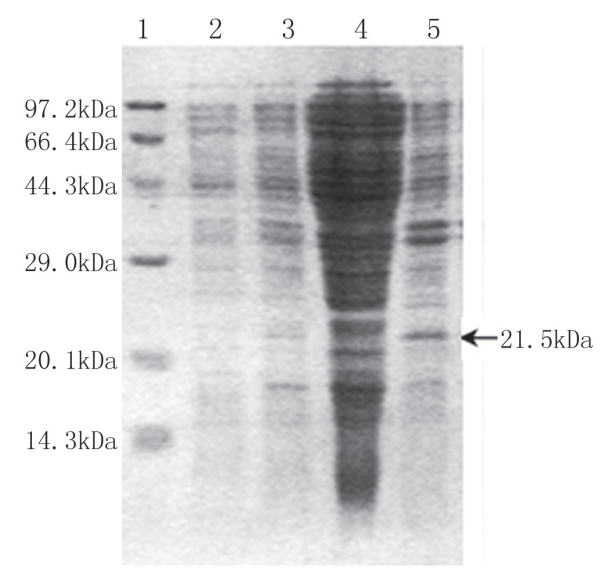

Figure 2. Expression of recombinant Hyp-1 protein (about 21.5 $\mathrm{kDa})$.

Lane 1, molecular weight marker; lane 2, total proteins in non-induced 'E. coli bacteria lysate; lane 3 , total proteins in induced $E$. coli bacteria lysate; lane 4, soluble proteins in induced E. coli; lane 5, insoluble proteins in induced $E$. coli. 
A

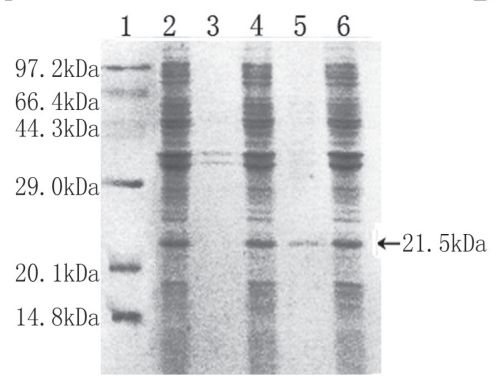

B

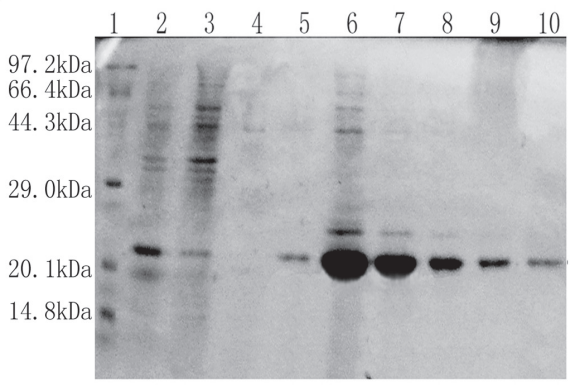

Figure 3. Solubilization and purification of recombinant Hyp-1 protein.

(A) Solubilization of recombinant protein. Lane 1, molecular weight marker; lane 2, pellet from sonicated IPTG-induced bacterial cells; lane 3, supernatant washed with buffer A (50 $\mathrm{mM}$ Tris/ $\mathrm{HCl}, 0.4 \mathrm{M} \mathrm{NaCl}, \mathrm{pH} 8.0$ ); lane 4, pellet washed with buffer A; lane 5, $2 \mathrm{M}$ ureasolubilized proteins; lane 6, pellet washed with $2 \mathrm{M}$ urea. (B) Purification of recombinant Hyp-1 protein. Lane 1, molecular weight marker; lane 2, 2 M urea-solubilized proteins; lane 3, flow-through of Ni-NTA column; lane 4, proteins eluted by $30 \mathrm{mM}$ imidazole; lanes 5-10, purified Hyp-1 fusion protein.

was generated which corresponded to the expected fragment length. DNA sequencing analysis of the pET22bHyp-1 construct showed that no mutations were found in the cDNA as compared with the deposited Hyp-1 sequence and that the cDNA was cloned in the correct reading frame for generation of the fusion protein (data not shown).

\section{Protein expression and purification}

SDS/PAGE analysis revealed that the fusion protein was expressed successfully in competent $E$. coli BL21 (DE3) cells (Fig. 2, lane 3) and that most of the target protein existed in insoluble fractions (Fig. 2, lane 5). This indicated that the target protein was mainly expressed as inclusion bodies in E. coli. Solubilization of the inclusion bodies with $2 \mathrm{M}$ urea at room temperature resulted in partial dissolution of the fusion protein (Fig. 3A, lane 5), whereas most of the other proteins in the inclusion bodies were not dissolved (Fig. 3A, lane 6), which was favorable for purification of the target protein. The soluble protein was purified by affinity chromatography using Ni-NTA columns (Fig. 3B). Finally, the recombinant protein was refolded by dialysis. The final concentration of the purified fusion protein was $0.6 \mathrm{mg} / \mathrm{ml}$.

\section{Characterization of the polyclonal antibody}

Western blotting and indirect ELISA were used to investigate the properties of the anti-Hyp-1 antibody. The western blot analysis confirmed that the purified protein could be recognized by the antiserum (Fig. 4, lane 4), whereas no obvious band was detected on the membrane with the preimmunized rabbit serum (Fig. 4, lane 3). These results indicated that we successfully purified the anti-Hyp-1 polyclonal antibodies. The antibody titers were determined by ELISA and were found to be approximately 1:256000 (Fig. 5). Preimmunized rabbit serum used as a negative control did not result in a detectable signal.

\section{Detection of endogenous Hyp-1 protein in $\boldsymbol{H}$. perforatum}

The polyclonal antibody was used to detect endogenous Hyp-1 protein in three different tissues by western blotting using the total protein of $A$. thaliana as a blank control (Fig. 6). A single band was revealed in the

three $H$. perforatum tissue samples, while no band was detected in the $A$. thaliana sample. The molecular weight of the band was approximately $17.8 \mathrm{kDa}$, which was consistent with the calculated molecular weight based on the amino acid sequence of the Hyp-1 protein. These results indicated that the antiserum had a high level of specificity to detect endogenous Hyp-1 protein in $H$. perforatum tissues.

\section{Immunofluorescence localization of Hyp-1 in $\mathrm{H}$. perforatum}

As shown in Fig. 7, Hyp-1 was present in all $H$. perforatum organs examined, including the leaf, stem and root. In the root, Hyp-1 was localized mainly in the cortex and primary phloem (Fig. 7A). In the stem, signal was only visualized in the primary phloem and no obvious signal was detected in other tissues (Fig. 7B). In the leaf (Fig. 7C, D), strong Hyp-1 signal was detected in both palisade and spongy mesophyll cells as well as the vascular bundle. However, no signal was detected in the dark gland (Fig. 7D), which was considered to be the site of accumulation of hypericin (Curtis \& Lersten, 1990; Fornasiero et al., 1998). To verify the reliability of the immunofluorescence technique, a blank control using PBS instead of antiserum as the primary antibody was performed; very little signal was detected (Fig. 7E, F), which indicated that the technique was reliable.

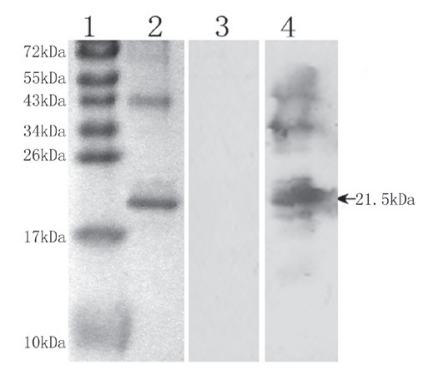

Figure 4. Western blotting analysis of anti-sera.

Lane 1, molecular weight marker; lane 2, purified protein separated on a $15 \%$ SDS/PAGE gel and then stained with Coomassie Blue R250; lane 3, purified protein incubated with preimmune rabbit serum as the negative control; lane 4, purified protein incubated with anti-Hyp-1 polyclonal antibody as the primary antibody.

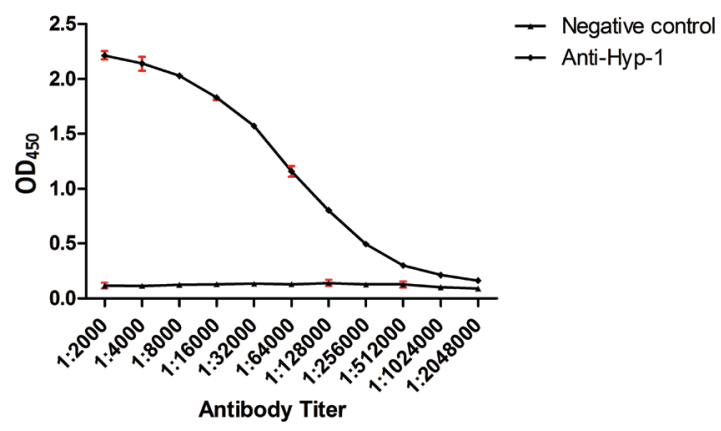

Figure 5. Determination of antibody titer by ELISA. 
A

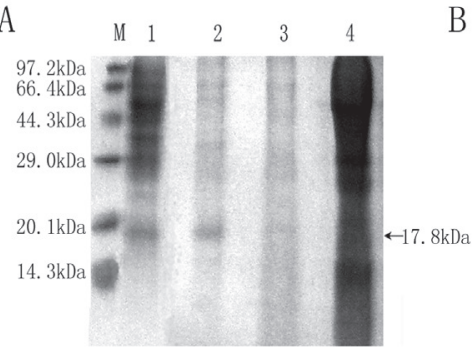

$\mathrm{B}$

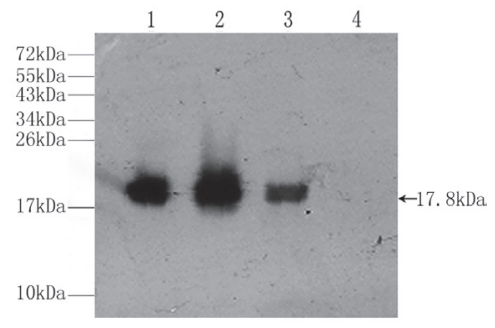

Figure 6. Detection of endogenous Hyp-1 protein (about $17.8 \mathrm{kDa}$ ) in $\mathrm{H}$. perforatum.

Protein samples were separated on a 15\% SDS/PAGE gel (A) and analyzed by western blotting with anti-Hyp-1 polyclonal antibody as the primary antibody (B). Lane 1, total proteins in calli of $H$. perforatum; lane 2, total proteins in plantlets of $H$. perforatum cultured in vitro; lane 3 , total proteins in transplants of $H$. perforatum cultured ex vitro; lane 4, total proteins in wild-type Arabidopsis thaliana; lane $\mathrm{M}$, molecular weight marker.

\section{Histochemical analysis of hypericins}

Hypericin and its derivatives were localized according to their physical and chemical properties. Hypericin is a red-colored anthraquinone derivative, which shows red fluorescence under ultraviolet light or blue light (Maggi et al., 2004), which changes to green after treatment with sodium hydroxide (Liang, 1988; Liu \& Hu, 1999). Many dark-red globules were present in all $H$. perforatum organs, including the leaf, stem and root (Fig. 8A-D). The substances in the globules exhibited the same color change after treatment with sodium hydroxide (Fig. 8E$\mathrm{H}$ ) and under excitation with blue light (Fig. 8I-K) as did the substances in the dark glands on the leaf (Fig. $8 \mathrm{G}, \mathrm{K})$. In the root, the globules were observed in all tissues except the primary xylem (Fig. 8A, E, I). In the stem, the globules were localized mainly in the epidermis, exodermis and endodermis (Fig. 8B, F, J). In the leaf, the globules were found in the epidermis and mesophyll cells (Fig. 8C, G, K, D, H).
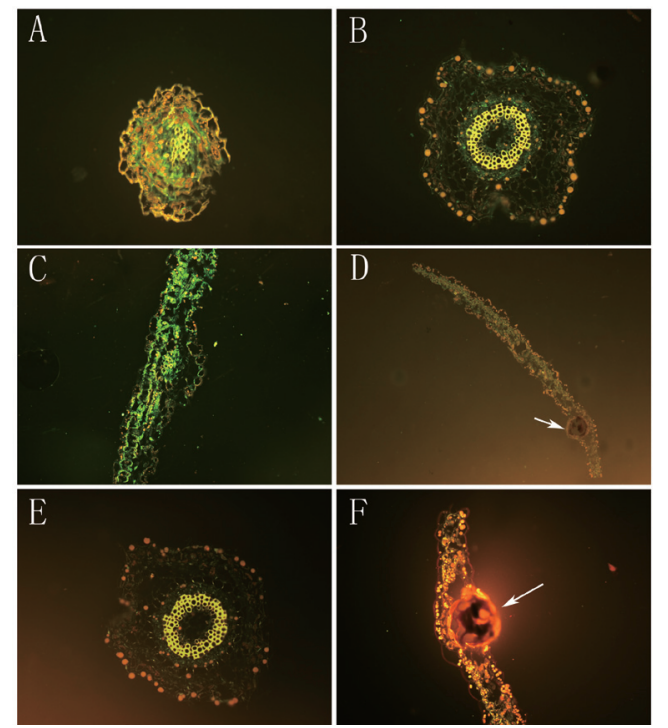

Figure 7. Immunofluorescence localization of Hyp-1 in different organs of red-pigmented $H$. perforatum plantlets.

The green signal represents Hyp-1 protein. (A) Tissue localization of Hyp-1 in the root (cortex and primary phloem). (B) Tissue distribution of Hyp-1 in the stem (primary phloem). (C-D) Tissue localization of Hyp-1 in the leaf (mesophyll and vascular bundle). (E-F) Blank control using PBS as the primary antibody; no obvious fluorescence was detected. Arrow points to the black gland.

\section{DISCUSSION}

Hypericin and its derivatives are major bioactive compounds synthesized by H. perforatum (Miller, 1998). It has been proposed that these chemicals are localized in dark glands present primarily on leaves (Curtis \& Lersten, 1990; Fornasiero et al., 1998). Zobayed et al. (2005, 2006) revealed that during the vegetative stage hypericin accumulated in the dark glands in leaf tissues only, but during the reproductive stage the dark glands located in flower tissues, especially in the stamen, acted as the major site for hypericin accumulation. In this study, we analyzed the distribution of hypericin and its derivatives in red-pigmented $H$. perforatum plantlets based on their physical and chemical properties. Our results showed that hypericins accumulated not only in the black glands but also in different tissues of the leaf, stem and root (Fig. 8). This raises the question of why hypericin is distributed differently in red-pigmented $H$. perforatum plantlets and in mature plants. One possible reason is that the distribution of hypericin changes during the development of $H$. perforatum plants. The physiological role of hypericin and its derivatives in plants is chemical defense against fungal infection and grazing by herbivores and phytophagous insects (Fields et al., 1990; Guillet et al., 2000). In mature plants the most vulnerable parts are leaves and the shoot apex, and hypericin also happens to be mainly accumulated in these areas. Similarly, the entire $H$. perforatum plantlet could conceivably be grazed by herbivores and insects. Consistent with this suggestion, hypericin accumulated in all organs of the plantlet, especially in the epidermal cells (Fig. 8).

According to previous studies, there are several hypotheses regarding the site of hypericin synthesis. First,

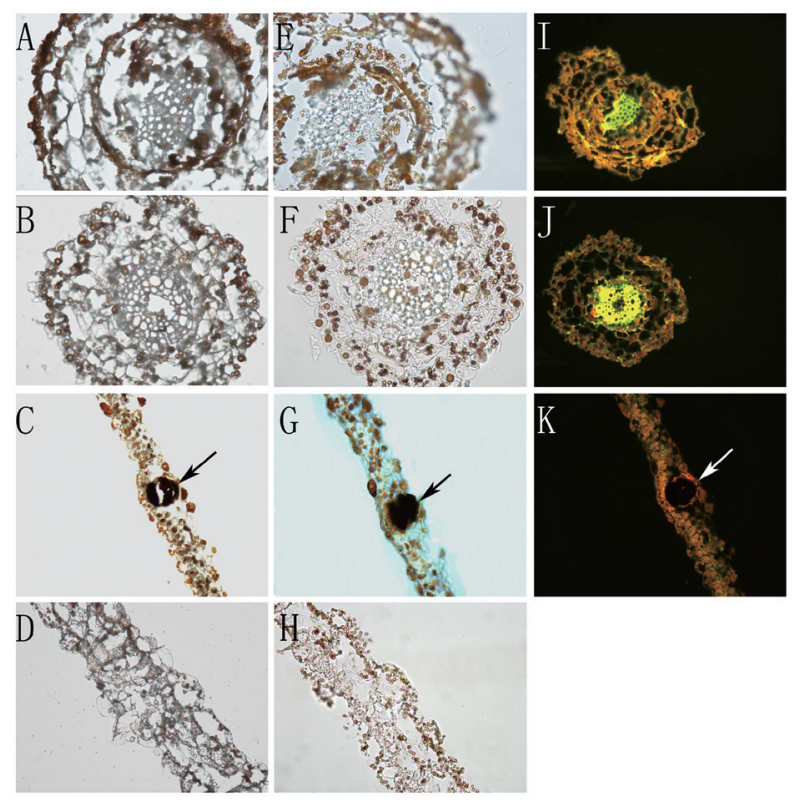

Figure 8. Histochemical analysis of hypericins in different organs of red-pigmented $H$. perforatum plantlets.

(A-D) Light micrographs of root (A), stem (B), and leaf (C, D). (E-F) Light micrographs of root (E), stem (F), and leaf (G, H) after incubation with $5 \% \mathrm{NaOH}$ for $10 \mathrm{~s}$ at room temperature. (I-K) Fluorescence micrographs of root (I), stem (J), and leaf (K) under blue light. Arrow points to the black gland. 
the black gland is not only the site of hypericin accumulation but also of its synthesis. Liu et al. (2002) studied the gradual substitution of substances in the gland cell vacuoles over the course of gland development and concluded that hypericin was synthesized in the black gland. Zobayed et al. (2006) researched the correlation between hypericin and its precursor emodin in different organs of $H$ perforatum and arrived at the same conclusion. Second, the peripheral sheath cells of the black gland might be the site of hypericin synthesis. Kornfeld et al. (2007) compared the differences in gland structure between two selected shoot cultures with different concentrations of hypericin and proposed that hypericin is produced in the peripheral cells rather than the interior cells. Third, hypericin might be synthesized in mesophyll cells and transported to the black gland. Onelli et al. (2002) analyzed the ultrastructure of the black gland in $H$. perforatum leaves at different developmental stages. Those authors hypothesized that secondary metabolite precursors and metabolic materials are generated in the mesophyll and imported into the gland apoplastically.

A prerequisite for biosynthesis of any metabolite in an organism is the presence of the enzyme(s) involved in its biosynthetic pathway. To date, the only known enzyme involved in the hypericin biosynthetic pathway is the protein encoded by Hyp-1 (Bais et al., 2003). Kosuth et al. (2007) studied Hyp-1 mRNA expression in different organs of $H$. perforatum seedlings in early stages of development. The gene was expressed in all organs of in vitro grown plants, with the highest level of $\mathrm{Hyp}_{\mathrm{p}-1}$ mRNA found in the roots. However, mRNA levels may or may not correlate with the protein level (Gygi et al., 1999; Futcher et al., 1999). Therefore, we generated polyclonal antibody to Hyp-1 protein and used it to investigate the tissue distribution of Hyp-1 in red-pigmented $H$. perforatum plantlets (Fig. 1). The Hyp-1 protein was widely expressed in different tissues of the leaf, stem and root (Fig. 7), consistent with its mRNA distribution (Kosuth et al. 2007). However, no signal was detected in the black gland (Fig. 7D), which is considered to be the accumulation site of hypericin (Curtis \& Lersten, 1990; Fornasiero et al., 1998). That suggested that hypericin was unlikely to be synthesized in the gland. It may be synthesized elsewhere in the plant and transported to the gland. Mesophyll cells might be the site of hypericin synthesis as strong Hyp-1 signal was detected in these cells (Fig. 7C), which is consistent with the hypothesis of Onelli et al. (2002). In addition, we also detected Hyp-1 protein in the endodermis and primary phloem of the root, the primary phloem of the stem, and the vascular bundle of the leaf. Hence, another possibility is that hypericin is generated in root and/or stem tissues and subsequently is transported to the gland; an example of such a mechanism is nicotine, which is synthesized in roots of tobacco plants and is transported to the leaf and other aerial tissues of the plant (Katoh et al., 2005). In this study, histochemical analysis showed that hypericin and its derivatives not only accumulated in the black gland but also in different tissues of the leaf, stem and root of red-pigmented $H$. perforatum plantlets (Fig. 8). Thus there might exist a transverse transport mechanism that could transport hypericin to the epidermis and cortex from the primary phloem. Further investigations are needed to test this hypothesis.

In conclusion, the results of this study indicate that hypericin accumulates not only in the black glands but also in other parts of the leaf, stem and root (Fig. 8), and that Hyp-1 protein is widely expressed in the leaf, stem and root of red-pigmented $H$. perforatum plantlets except in the black gland (Fig. 7). Hypericin might be synthesized in mesophyll cells or in tissues of the root and/or stem, and be then transported to the gland and other sites of accumulation by a transverse and vertical transport mechanism. The antibody generated in this study will provide a basis for further study on the regulatory mechanism of hypericin synthesis during the development of $H$. perforatum.

\section{Acknowledgments}

We are grateful to Jiahao Shi and Zhejin Sheng for assistance with rabbit immunization and western blotting.

\section{REFERENCES}

Agostinis P, Vantieghem A, Merlevede W, Witte PA (2002) Hypericin in cancer treatment: more light on the way. Int J Biochem Cell Biol 34: 221-241.

Bais HP, Vepachedu R, Lawrence CB, Stermitz FR, Vivanco JM (2003) Molecular and biochemical characterization of an enzyme responsible for the formation of hypericin in St. John's wort (Hypericum perforatum L.). J Biol Chem 278: 32413-32422.

Bradford MM (1976) A rapid and sensitive method for the quantitation of microgram quantities of protein utilizing the principle of protein-dye binding. Anal Biochem 72: 248-254.

Curtis JD, Lersten NR (1990) Internal secretory structures in Hypericum (Clusiaceae): H. perforatum L. and H. Balearicum L. New Phytol 114: $571-580$.

Fernandes H, Konieczna M, Kolodziejczyk R, Bujacz G, Sikorski M, Jaskolski M (2008) Crystallization and preliminary crystallographic studies of Hyp-1, a St. John's wort protein implicated in the biosynthesis of hypericin. Acta Crystallogr., Sect F: Struct Biol Cryst Commun 64: 405-408.

Fields PG, Arnason JT, Fulcher RG (1990) The spectral properties of Hypericum perforatum leaves: the implications for photoactivated defenses. Can J Bot 68: 1166-1170.

Fornasiero RB, Bianchi A, Pinetti A (1998) Anatomical and ultrastructural observations in Hypericum perforatum L. leaves. J Herbs, Spices and Med Plants 5: 21-23.

Futcher B, Latter GI, Monardo P, Mclaughlin CS, Garrels JI (1999) A sampling of the yeast proteome. Mol Cell Biol 11: 7357-7368.

Guillet G, Podeszfinski C, Regnault-Roger C, Arnason JT, Philogene BJR (2000) Behavioral and biochemical adaptations of generalist and specialist herbivorous insects feeding on Hypericum perforatum (Guttiferae). Environ Entomol 29: 135-139.

Gygi SP, Rochon Y, Franza BR, Aebersold R (1999) Correlation between protein and mRNA abundance in yeast. Mol Cell Biol 3: 1720-1730.

Karioti A, Bilia AR (2010) Hypericins as potential leads for new therapeutics. Int J Mol Sci 11: 562-594.

Katoh A, Ohki H, Inai K, Hashimoto T (2005) Molecular regulation of nicotine biosynthesis. Plant Biotechnol 22: 389-392.

Kornfeld A, Kaufman PB, Lu CR, Gibson DM, Bolling SF, Warber SL, Chang SC, Kirakosyan A (2007) The production of hypericins in two selected Hypericum perforatum shoot cultures is related to differences in black gland structure. Plant Physiol Biochem 45: 24-32.

Kosuth J, Katkovcinová Z, Olexová P, Cellárová E (2007) Expression of the hyp-1 gene in early stages of development of Hypericum perforatum L. Plant Cell Rep 26: 211-217.

Laemmli UK (1970) Cleavage of structural proteins during assembly of the head of bacteriophage T4. Nature 277: 680-685.

Liang XY (1988) Advances in Hypericum L. Guibaja 18: 256-262.

Liu CD, Kwan D, Saxton RE, McFadden DW (2000) Hypericin and photodynamic therapy decreases human pancreatic cancer in vitro. J Surg Res 93: 137-143.

Liu W, Lu H, Hu ZH (2002) Ultrastructure of the multicellular nodules in Hypericum perforatum leaves. Acta Bot Sin 44: 649-656.

Liu WZ, Hu ZH (1999) The secretory structure of Hypericum perforatum and its relation to hypericin accumulation. Acta Bot Sin 41: 369-372.

Maggi F, Ferretti G, Pocceschi N, Menghini L, Ricciutelli M (2004) Morphological, histological and phytochemical investigation of the genus Hypericum of central Italy. Fitoterapia 75: 702-711.

Maidment I (2000) The use of St. John's wort in the treatment of depression. Psychiat Bull 24: 232-234.

Michalska K, Fernandes H, Sikorski M, Jaskolski M (2010) Crystal structure of Hyp-1, a St. John's wort protein implicated in the biosynthesis of hypericin. J Struct Biol 169: 161-171.

Miller AL (1998) St. John's wort (Hypericum perforatum): clinical effects on depression and other conditions. Altern Med Rev 3: 18-26. 
Miskovsky P (2002) Hypericin — A new antiviral and antitumor photosensitizer: mechanism of action and interaction with biological macromolecules. Curr Drug Targets 3: 55-84.

Onelli E, Rivetta A, Giorgi A, Bignami M, Cocucci M, Patrignani G (2002) Ultrastructural studies on the developing secretory nodules of Hypericum perforatum. New Phytol 197: 92-102.

Sambrook J, Russell DW (2001) Molecular Cloning: A Laboratory Manual, Cold Spring Harbor Laboratory Press, New York.

Stevinson C, Ernst E (1999) Hypericum for depression. An update of the clinical evidence. Eur Neuropsychopharm 9: 501-505.
Taher MM, Lammering GM, Hershey CM, Valerie KC (2002) Moodenhancing antidepressant St. John's wort inhibits the activation of human immunodeficiency virus gene expression by ultraviolet light. IUBMB Life 54: 357-364.

Zobayed SMA, Afreen F, Kozai T (2005) Temperature stress can alter the photosynthetic efficiency and secondary metabolite concentrations in St. John's wort. Plant Physiol Bioch 43: 977-984.

Zobayed SMA, Afreen F, Goro E, Kozai T (2006) Plant-environment interactions: accumulation of hypericin in dark glands of Hypericum perforatum. Ann Bot 98: 793-804. 